\title{
INSTITUCIONALIZAÇÃO DE CRIANÇAS E ADOLESCENTES E A ADOÇÃO TARDIA EM UNIÃO DA VITÓRIA-PR
}

\section{INSTITUTIONALIZATION OF CHILDREN AND ADOLESCENTS AND THE LATE ADOPTION IN UNION OF VITÓRIA-PR}

\author{
Maria Luiza Milani ${ }^{1 *}$, Karine Santos ${ }^{2}$, Jairo Marchesan ${ }^{3}$, Sandro Luiz Bazzanella ${ }^{4}$ \\ 1 Graduada em Serviço Social (Faculdade Espírita); Mestre em Educação (UFSM); Doutora em Serviço Social, Movimentos Sociais e \\ Políticas Sociais (PUC/SP). Docente do Programa de Mestrado em Desenvolvimento Regional da Universidade do Contestado. E- \\ mail: marialuiza@unc.br \\ 2 Graduada em Serviço Social (UNIGUAÇU). Atua da pós-graduação no IMAS. E-mail: kahrine-s@hotmail.com \\ ${ }^{3}$ Graduado em Estudos Sociais/Geografia (UNOESC); Mestre em Educação nas Ciências - Geografia (UNIJUÍ); Doutor em Geografia \\ (UFSC). Professor do Programa de Mestrado em Desenvolvimento Regional da Universidade do Contestado. E-mail: jairo@unc.br \\ ${ }^{4}$ Graduado em Filosofia (FFCLDB/RS); Mestre em Educação e Cultura (UDESC); Doutor em Ciências Humanas (UFSC). Professor do \\ Programa de Mestrado em Desenvolvimento Regional da Universidade do Contestado. E-mail: sandro@unc.br
}

\section{Resumo}

O objetivo do estudo foi analisar a adoção tardia e os serviços prestados pela rede de proteção social integral da criança e do adolescente institucionalizada em União da Vitória-PR, após a Lei no 8.069/1990. Foi realizada pesquisa bibliográfica e de campo sobre a composição da rede socioassistencial que atua tanto na proteção como na adoção tardia. Aplicou-se entrevista para seis agentes da rede, sendo: 02 no Centro de Referência de Assistência Social (CRAS); 02 no Centro de Referência Especializado de Assistência Social (CREAS); 01 na Vara da Infância e Juventude e 01 no Conselho Tutelar. A coleta de dados ocorreu nas instituições em 2018. Percebeu-se que a proteção social integral da criança e do adolescente, que modificou a institucionalização naquele município, estava articulada quanto a adoção tardia, mas enfrentava desafios. Atores envolvidos não compreendiam a complexidade desse processo e impediam a operacionalidade dos trâmites para adoção. A adoção tardia é um desafio na garantia do direito à convivência familiar. Uma criança ou adolescente que passou por negligências e foi institucionalizada em muitos casos resta a opção da adoção, o que também se torna um novo desafio: o de ser aceito em especial se tiver mais de dois anos de idade. Concluiu-se que esta é uma questão a ser enfatizada tanto no viés das atribuições institucionais, quanto dos profissionais que atuam na área, sob o risco de consolidar mitos e contradições que culturalmente persistem e afetam sobremaneira as mudanças nas bases e trâmites da adoção tardia no Brasil.

Palavras-chave: Criança e Adolescente. Adoção Tardia. Rede de Proteção.

\begin{abstract}
The aim of this study was to analyze the late adoption and services provided by the social protection network of children and adolescents institutionalized in União da Vitória-PR, after Law No. 8,069/1990. A bibliographic and field research was carried out on the composition of the social assistance network that acts both in protection and in late adoption. Interviews were applied to six network agents, being: 02 at the Reference Center for Social Assistance (CRAS); 02 at the Specialized Reference Center for Social Assistance (CREAS); 01 in the Court of Childhood and Youth and 01 in the Guardianship Council. Data collection occurred in institutions in 2018. It was noticed that the integral social protection of children and adolescents, which modified institutionalization in that municipality, was articulated regarding late adoption, but faced challenges. Actors involved did not understand the complexity of this process and prevented the operationality of the procedures for adoption. Late adoption is a challenge in guaranteeing the right to family life. A child or adolescent who has been neglected and institutionalized in many cases remains the option of adoption, which also becomes a new challenge: to be accepted especially if he is more than two years of age. It was concluded that this is an issue to be emphasized both in the bias of institutional attributions and of professionals working in the area, at the risk of consolidating myths and contradictions that culturally persist and greatly affect changes in the bases and procedures of late adoption in Brazil.
\end{abstract}

Keywords: Child and teenager. Late adoption. Protection net

CUNIS-MG. All rights reserved. 


\section{INTRODUÇÃO}

A proteção social integral da criança e do adolescente que modifica a institucionalização e a adoção tardia no Brasil é uma temática constitucional relativamente recente e, por isso, necessita ser avaliada, refletida e debatida permanentemente.

A desigualdade social brasileira, provocada pela conjuntura política, social e principalmente econômica, atinge diretamente parte das crianças e dos adolescentes, os quais são um dos segmentos mais vulneráveis da sociedade atual. Isso ocorre devido às situações de risco, negligência, condições socioeconômicas, violência, dentre outras, decorrentes da vulnerabilidade em que as crianças e adolescentes estão expostas. Por vezes, tais situações são resultantes da negligência e violência por parte da família, da sociedade ou mesmo do Estado. Estes entes institucionais que deveriam proteger, por vezes, ou, em partes, colaboram para o abandono, a potencialização da violência e, consequentemente, com a necessidade da intervenção do Estado para a institucionalização de processos de adoção.

No cenário social brasileiro os debates sobre a temática da criança e do adolescente são mais intensos a partir da década de 1980. Afinal, foi nesse período que ocorreu o processo de transição político-democrático, do movimento das "Diretas Já", das lutas por direitos trabalhistas, sociais, políticos e civis. Foi um período favorável à discussão política, à discussão das temáticas que envolviam problemas da sociedade brasileira da época, bem como, de maior participação e protagonismo dos movimentos sociais, os quais contribuíram para ampliar e intensificar o debate sobre diferentes situações que envolviam a sociedade. Naquele contexto, já na década de 1990, um dos avanços relevantes foi o Estatuto da Criança e do Adolescente (ECA), que possibilitou inverter a ordem da proteção social destinada às crianças e adolescentes brasileiras.

Silva (2005) destaca que o ECA se configura em um avanço ímpar sobre o Código de Menores de $1979^{1}$. As diretrizes do ECA, além de assegurarem uma política de proteção social integral ao segmento da criança e do adolescente, reformularam a legislação menorista e o sistema da justiça juvenil.

Essa luta política, histórica e jurídica culmina com o ECA (SILVA, 2005). Esse resultado é proveniente do esforço coletivo, quando, em março de 1988, se reúne e se constitui o "Fórum Nacional Permanente das Organizações da Sociedade Civil de Defesa dos Direitos da Criança e do Adolescente". A luta social reunida nesse Fórum tinha duas vertentes: uma era a de desenvolver ações ao combate à violência às crianças e adolescentes; a segunda vertente era a de organizar a participação das Organizações da Sociedade Civil (OSC) na Assembleia Constituinte. Esse fórum teve importância na conquista das garantias constitucionais expressas nos artigos 226, 227 e 228 da Constituição da República Federativa do Brasil (CRFB), de 1988. Tais artigos (proteção integral da criança e do adolescente) inovaram por compartilhar as responsabilidades entre a família, a sociedade e o Estado, os quais devem assegurar a esse segmento (crianças e adolescentes), vida digna, com acesso à saúde, educação, lazer, alimentação, abrigo, convívio familiar e comunitário. Aos três entes responsáveis (Estado, família e sociedade) cabe salvaguardar as crianças e adolescentes de todas as formas de violência, negligência, crueldade e outras que possam ferir a vida e a dignidade, conforme preconiza a Legislação.

\footnotetext{
${ }^{1}$ Em 1927, foi publicado o Decreto 17.943-A, a primeira legislação acerca da infância no Brasil, denominado Código de Menores Mello Matos. Esse decreto trouxe diversas inovações: disciplinava o trabalho das crianças, definia o "menor perigoso" decorrente da situação de pobreza (menor=criança pobre). Tanto que a criança dita "normal", quando havia algum conflito, era atendida pela Vara de Família, enquanto que a "criança pobre" era atendida pelo Juizado de Menores.
} 
Art. 226. A família, base da sociedade, tem especial proteção do Estado (EC no 66/2010).

Art. 227. É dever da família, da sociedade e do Estado assegurar à criança, ao adolescente e ao jovem, com absoluta prioridade, o direito à vida, à saúde, à alimentação, à educação, ao lazer, à profissionalização, à cultura, à dignidade, ao respeito, à liberdade e à convivência familiar e comunitária, além de colocá-los a salvo de toda forma de negligência, discriminação, exploração, violência, crueldade e opressão (EC no 65/2010), § 1‥ O Estado promoverá programas de assistência integral à saúde da criança, do adolescente e do jovem, admitida a participação de entidades não governamentais, mediante políticas específicas e obedecendo aos seguintes preceitos: [...] § 3o O direito à proteção especial abrangerá os seguintes aspectos: [...] $\mathrm{V}$ - obediência aos princípios de brevidade, excepcionalidade e respeito à condição peculiar de pessoa em desenvolvimento, quando da aplicação de qualquer medida privativa da liberdade; VI estímulo do Poder Público, através de assistência jurídica, incentivos fiscais e subsídios, nos termos da lei, ao acolhimento, sob a forma de guarda, de criança ou adolescente órfão ou abandonado; § 50 A adoção será assistida pelo Poder Público, na forma da lei, que estabelecerá casos e condições de sua efetivação por parte de estrangeiros. § 6o Os filhos, havidos ou não da relação do casamento, ou por adoção, terão os mesmos direitos e qualificações, proibidas quaisquer designações discriminatórias relativas à filiação.

Art. 228. São penalmente inimputáveis os menores de dezoito anos, sujeitos às Normas da legislação especial.

$\mathrm{Na}$ atual conjuntura política, social e econômica do Brasil, contribuem para os agravos sociais, dentre eles a exclusão de famílias e indivíduos. A desigualdade, a exploração e a discriminação são situações que se somam a outras, como, por exemplo, a pobreza, doenças, desemprego, que geram a exclusão e a vulnerabilidade de crianças e adolescentes. Tais situações se expressam e se manifestam em um dos segmentos sociais mais vulneráveis, as crianças e os adolescentes. Essa exclusão faz com que as expressões da questão social se evidenciem sobre esse segmento populacional que por si só já é vulnerável, pela condição de ser, de se apresentar como um ser em desenvolvimento e quando ocorrem violências, abandono, impossibilidade de manutenção de crianças e adolescentes no ambiente familiar pela pobreza ou riscos, ocorre a institucionalização.

Portanto, o argumento central deste artigo coloca em debate quais os fundamentos teóricos, legais e jurídicos que sustentam as transformações sociais no trato da criança e do adolescente brasileiro nos processos de adoção tardia. Assim, o objetivo geral do artigo é o de apresentar o arcabouço teórico que aporta a proteção social, bem como as legislações que sustentam o processo de adoção tardia no Brasil.

O artigo aborda inicialmente a base teórica contemplando a instituição familiar, sob dois aspectos: da vulnerabilidade que leva à perda de filhos para a institucionalização e adoção e, a família que, por diferentes motivos, opta por inserir membros e escolhe a adoção para esse fim. Complementa o artigo, a complexa e polêmica situação da adoção tardia que, entre mitos e contradições, ocorre no âmbito da proteção social integral destinada ao segmento da criança e do adolescente.

Na sequência, o artigo apresenta um processo concreto, situado em um recorte territorial o município de União da Vitória (PR) -, e nele situa aspectos acerca da rede socioassistencial e a promoção da adoção tardia de crianças e adolescentes. 


\section{FAMÍLIA: CRIANÇA E ADOLESCENTE E ADOÇÃO TARDIA}

A relação da criança e do adolescente com a família, bem como a adoção e relações familiares, nesse contexto, se realiza sob a proteção do Estado, em forma de leis e operadas pelos entes institucionais responsáveis por assegurar a proteção social integral ao segmento.

Nogueira Neto (2005) argumenta sobre a necessidade de se erigir ações, programas, políticas públicas, decisões judiciais, legislação, mobilização e atuação da sociedade civil, que expressem a perspectiva dos direitos, integrado em sistema de garantia de direitos da criança e do adolescente.

A família, entendida como a instituição social na qual convivem diversas pessoas agrupadas, possuem "[...] um conjunto de normas, práticas e valores que têm seu lugar, seu tempo e uma história. É uma construção social, que vivenciamos [...]” (BIROLI, 2014, p.07).

$\mathrm{Na}$ recente realidade social brasileira, se constata diversidade de arranjos familiares, nos quais se vivem as relações familiares e sociais, os afetos e sentimentos que são trocados, porém, se vivem as ameaças: negligências, riscos e vulnerabilidades que levam a medidas de intervenção pelo Estado nas organizações familiares com sequente institucionalização particularmente de crianças e adolescentes. O Estado recebeu por meio da CRFB, de 1988, a atribuição de resguardar o bem-estar desse segmento.

Para Biroli (2014), a noção de família pode estar ligada a afetos e sentimentos, de diferentes tipos e às experiências que as pessoas têm das relações familiares que são singulares, íntimas e fundamentais para a percepção de quem as pessoas são, isto é, para a constituição de identidades. Família é uma realidade social e institucional, profundamente política, tanto nos fatores que a condicionam, quanto em seus desdobramentos que a modernidade proporcionou, tais como a revisão dos valores que marcaram as relações de poder no seu ambiente íntimo, como também, as responsabilidades familiares coletivizadas entre a sociedade e o Estado.

No contexto dessas revisões, as legislações corroboraram direitos e deveres em relação às crianças e adolescentes. De tal modo, que no artigo 20 do ECA consta que os filhos gerados nas uniões estáveis ou por adoção, terão os mesmos direitos e qualificações, proibida qualquer denominação discriminatória relativa à filiação. Ou seja, é filho, independentemente da constituição familiar.

Dias (2015) esclarece que a disciplina da nova filiação há que se edificar sobre três pilares constitucionalmente fixados: a plena igualdade entre os filhos, desvinculação do filho do estado civil dos pais e a doutrina da proteção integral. Reportando ainda aos argumentos de Dias (2015), pode-se dizer que, no moderno direito de filiação, o formato tradicional de família deu lugar à sua democratização, e as relações são mais de igualdade e de respeito mútuo, traço fundamental à lealdade e afetividade.

Ocorreram alterações nos arranjos familiares e as configurações atuais compreendem uma formação familiar contemplando gerações (avós, pais, netos, bisnetos), em especial entre os grupos sociais mais vulneráveis. Porém, uma prática comum ainda é a criança e/ou adolescente estarem sob a responsabilidade da mãe. Diferentes fatores têm levado os pais a se eximirem de suas atribuições familiares para com os filhos. Nessa direção, o acúmulo de afazeres e responsabilidades das mães podem proporcionar situações de negligência e riscos sociais. Observa-se que no processo da institucionalização quando o caso já está definido para adoção pela justiça (Vara da Infância e Juventude), a luta pela adoção conta com auxílio da rede de proteção, mas geralmente há morosidade. Muitas famílias que estão à espera para adotarem um 
filho, colocam critérios, o que torna complexa a situação de crianças e adolescentes institucionalizados que não se enquadram de forma suficiente em tais critérios. Ocorre que, em muitas situações, acontece certa "idealização" de filho. Ou seja, a escolha por uma criança ou adolescente se assemelha à opção por um bem material a ser adquirido, ou já adquirido. Essa situação, por vezes, torna perversa a tramitação de um processo de adoção, pois gera expectativas, sentimentos e esperança que podem causar frustrações nos adotáveis. Este tem sido um agravante para que a adoção se torne tardia.

A adoção tardia também é decorrente da institucionalização tardia, quando pais ou familiares não têm condições de permanecerem com os filhos biológicos, dadas as situações de abandono, negligências ou violências. Esta situação se agrava com a morosidade do processo de adoção, quanto de demora significativa. Ou seja, são vários os fatores que implicam e colaboram para que a adoção tardia ocorra.

A Constituição da República Federativa do Brasil de 1988 avançou nesta direção, e em seu artigo 227 rompe com a discriminação legal até então vigente, determinando que filhos adotivos e biológicos sejam iguais em direitos, posteriormente regulamentado na Lei 8.069, de 13 de julho de 1990 do Estatuto da Criança e do Adolescente (ECA).

O ECA, em acordo com a Constituição de 1988 define que toda a criança e adolescente são sujeitos de direitos, merecedores da proteção especial, ocupando o tema da adoção nos artigos 39 a 52. Com o ECA a adoção passa a atribuir a condição de filho ao adotado com os mesmos direitos e deveres, inclusive sucessórios, desligando-o de qualquer vínculo com os pais e parentes naturais, salvo os impedimentos matrimoniais previsto no artigo 41 . 0 adotado não poderá mais herdar dos pais biológicos e não poderá receber pensão alimentícia, mesmo que ocorra a morte dos adotantes não será restabelecido o poder familiar dos pais naturais. Essas Leis tentam resguardar ao máximo os direitos de uma criança ou adolescente que estava em processo de adoção.

Mas, tanto para a criança como para o adolescente, a adoção tardia pode ser um dilema que vai repercutir no seu desenvolvimento e modo de vida cotidianos. Conforme a literatura, o tardio está relacionado com a idade e para as crianças e adolescentes, no que tange à adoção, uma criança com mais de dois anos de idade é incluída na categoria de adoção tardia. Vargas (1998) argumenta que o tardio se refere à criança com mais de dois anos.

Na cultura brasileira há uma prática de adoção de crianças recém-nascidas, com medo de adotar crianças e adolescentes com mais idade, por essas trazerem consigo uma bagagem de conhecimentos culturais e sociofamiliares em que viviam.

As contradições que existem em torno da adoção podem ser mostradas pelos índices. Em publicação no jornal digital "Folha de Londrina", Carolina Avansini (2017) apresenta dados do Conselho Nacional de Justiça (CNJ) (S/D). Este conselho realizou pesquisa no ano de 2016 e, naquele ano, havia 39.051 pretendentes cadastrados. Destes, 17.359 pretendentes aceitariam crianças de outras etnias, e 26.327 pretendentes à adoção aceitavam adotar irmãos. $O$ total de crianças e adolescentes cadastrados para adoção nesse ano era de 7.322. Destas, 3.314 tinham até 10 anos, e 4.008 de 11 a 17 anos. Do total de crianças e adolescentes cadastrados, 3.257 eram do sexo feminino e 4.065 do sexo masculino; e 4.506 possuíam irmãos.

Essa reportagem mostrou ainda que no estado do Paraná havia um total de pretendentes à adoção de 4.034, para um total de 881 crianças ou adolescentes cadastrados para serem adotados. 
As contradições se forjam a partir de mitos, e estes, conforme Camargo (2006), expõem aspectos constitutivos da atual cultura da adoção no Brasil como obstáculos à realização de adoções de crianças mais velhas. Mas, Simon (2005, p. 46), alerta que "[...] as características das crianças e adolescentes afastados de suas famílias originais vão paulatinamente distanciando-se do perfil desejado pela maioria dos adotantes". Nova perspectiva, o medo do desconhecido é um fator que influencia na adoção tardia, pois existe a preocupação que não se consiga superar os acontecimentos do passado podendo interferir no presente e no futuro.

Para Camargo (2006, p. 71), esse pensamento é mais um mito que dificulta a cultura da adoção. Diz o autor que os mitos quanto à criança adotada são: não estabelecer vínculos com os pais adotivos; laços de sangue em que o fator biológico regerá o destino final e quase sempre trágico nos casos de adoção. Mito da revelação da origem da criança; e, a compensação por afeto que fazem os pais adotivos destinarem afeto e atenção à criança pela sua condição de origem.

Em relação aos preconceitos e busca da criança perfeita, apresenta-se o mito da criança das fadas (ANDREI, 2001). Segundo uma lenda do tempo dos Celtas, a criança era vista como absolutamente pura, sem interferências consanguíneas do processo de gestação. Nesta direção, o preconceito racial se confirma quando a maior procura é por crianças loiras e não aquelas com peles negra ou parda. A contradição nessa questão é que a família brasileira é naturalmente multirracial e mais de $50 \%$ é de origem étnica afrodescendente.

Sobre a adoção tardia e seus problemas, seguindo o pensamento de Andrei (2001, p. 48), esta alerta que o problema não é encontrar filhos para pais angustiados, mas sanar a angústia de crianças sem pais. Portanto, a adoção tardia é um desafio! Além das eventuais dúvidas e incertezas, é um processo que precisa ser construído coletivamente entre pais e filhos, e também pela sociedade. Além disso, é um processo que precisa desmistificar mitos e preconceitos. Afinal, toda criança ou adolescente tem o direito de acesso e convívio familiar.

\section{MATERIAIS E MÉTODO}

O estudo desenvolvido caracteriza-se pela abordagem qualitativa, de tipo exploratório, com procedimentos de pesquisa bibliográfica e de campo. Após finalizados os estudos teóricos, procedeu-se o reconhecimento de entes institucionais existentes, indicados pelas legislações e se conseguiu identificar a rede socioassistencial em operação no município de União da Vitória-PR (Figura 01), envolvida com a proteção social integral, desde os serviços da proteção social básica, aos da média complexidade da Política Pública de Assistência Social (PPAS), bem como, os entes institucionais da justiça (Vara da Infância e da Juventude do Município). 


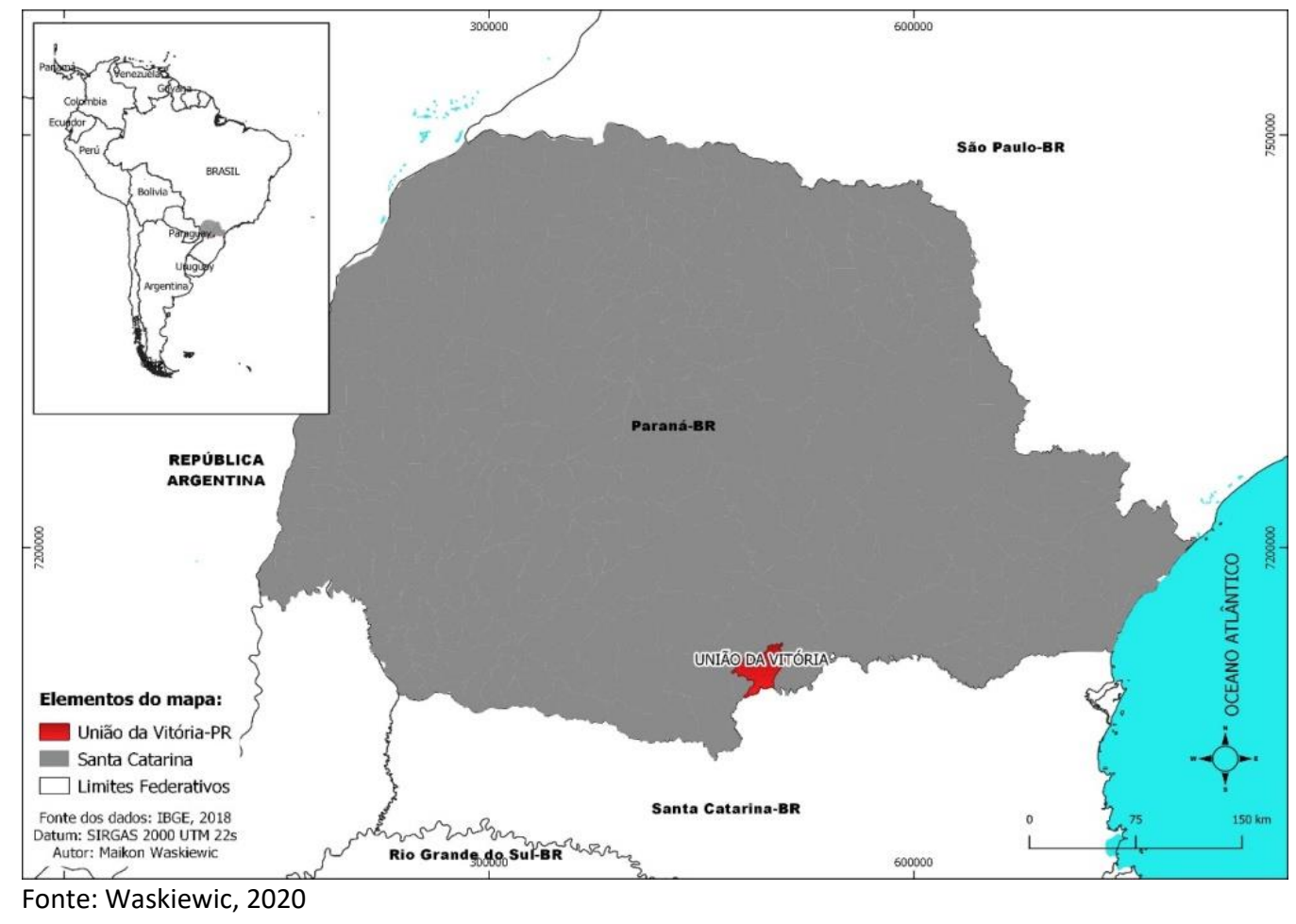

Figura 1 - Localização do município de União da Vitória (PR)

A pesquisa de campo seguiu roteiro apresentado aos profissionais que estavam envolvidos diretamente com os processos de adoção. Aplicou-se uma entrevista para seis agentes: Centro de Referência de Assistência Social (CRAS), 02 profissionais; Centro de Referência Especializado de Assistência Social (CREAS), 02 profissionais; Vara da Infância e Juventude, 01 entrevistado e Conselho Tutelar, 01 entrevistado. Estes profissionais assinaram o Termo de Consentimento Livre Esclarecido (TCLE), após a liberação para a realização da pesquisa pelo Núcleo de Ética e Bioética (NEB), autorizado pelo número de protocolo 2018/249.

A coleta de foi realizada com seis entrevistas, aplicada individualmente e de forma presencial. Foram feitos contatos preliminares para o agendamento da visita institucional e coleta de dados Por fim, extraíram-se os dados e relatos mais relevantes ou fragmentos das entrevistas acerca do objeto desta pesquisa, que foram analisados e interpretados à luz das bases teóricas. Para a realização desse procedimento final, foi utilizada a análise de conteúdo, em suas três etapas. Para orientar o processo da análise de conteúdo, foram utilizadas as questões norteadoras da pesquisa. A partir de cada uma das questões os materiais foram selecionados, agrupados, analisados finalizando-se com uma reflexão como forma de responder cada questão norteadora.

\section{RESULTADOS E DISCUSSÕES}

\subsection{Quanto à Rede e à Proteção Social Integral}

No Brasil, o Estatuto da Criança e do Adolescente (ECA), Lei 8.069, de 1990, considera criança a pessoa até 12 anos de idade, incompletos. De igual modo, define a adolescência como a faixa etária de 12 a 18 anos de idade (artigo $2^{\circ}$ ), e, em casos excepcionais e quando disposto na lei, o estatuto é aplicável para pessoas com até os 21 anos de idade (artigos 121 e 142).

Importante destacar a doutrina da proteção integral e reconhecer a criança e o adolescente como sujeitos de direitos, estabelecendo a necessidade de proteção e cuidados especiais, substituindo a doutrina da situação irregular anterior. Essa Doutrina de Proteção 
Integral foi inserida pela Constituição Federativa do Brasil, de 1988, através de seu artigo 227 e, posteriormente, pelo Estatuto da Criança e do Adolescente (ECA), de 1990.

A rede de proteção social integral para a criança e o adolescente de União da Vitória-PR, deve estar estruturada e atenta a todas as questões voltadas ao público infanto-juvenil do município. De forma articulada, deverá realizar suas ações para a promoção do bem-estar e da segurança da criança e do adolescente.

O atendimento deve ser realizado com ênfase na construção e no fortalecimento de vínculos comunitários, reintegrando sua participação social e enfatizando o desenvolvimento da autonomia dos usuários. Os serviços prestados por um ente denominado família acolhedora, (Resolução 109/2009), é a organização do acolhimento de crianças e adolescentes afastados de suas famílias originárias para sua proteção, nas residências de famílias que são cadastradas. A legislação vigente e acima anunciada mantém a garantia do direito de possibilidade da criança e do adolescente poder voltar à sua família biológica quando não ocorre a possibilidade de adoção. Esse serviço deve ser organizado conforme o que está previsto no Estatuto da Criança e do Adolescente em suas diretrizes, princípios e orientações.

A Casa-Lar é um serviço de acolhimento, oferecido em unidades residenciais, contendo ao menos uma pessoa ou casal que trabalhe como cuidador e educador residente em um lugar que não é seu. Segundo as orientações técnicas, para atuar nos serviços de acolhimento para crianças e adolescentes, elaborado pelo Ministério de Desenvolvimento Social (MDS) (2009), essas pessoas atuam como cuidadores de crianças e adolescentes que por algum motivo foram afastados do seu convívio familiar, seja por violência, abandono ou outras questões que impossibilitem o convívio de proteção da família.

O acolhido fica nesse serviço até que os laços familiares sejam fortalecidos, ou na impossibilidade dessa questão acontecer realiza-se o encaminhamento para família substituta, por meio da adoção. Esse serviço deve ser organizado próximo de uma rotina familiar, oferecendo às crianças e adolescentes oportunidades de reinserção familiar, ou em uma família substituta, bem como o convívio social.

$\mathrm{Na}$ investigação sobre a Rede de Proteção Social da Criança e do Adolescente do município de União da Vitória-PR, identificou-se que essa rede estava constituída pelos seguintes setores e serviços: Centro de Referência de Assistência Social (CRAS), Centro de Referência Especializado de Assistência Social (CREAS), Vara da Infância e Juventude e Conselho Tutelar, os quais estão envolvidos com a adoção tardia, como se pode observar na figura 2.

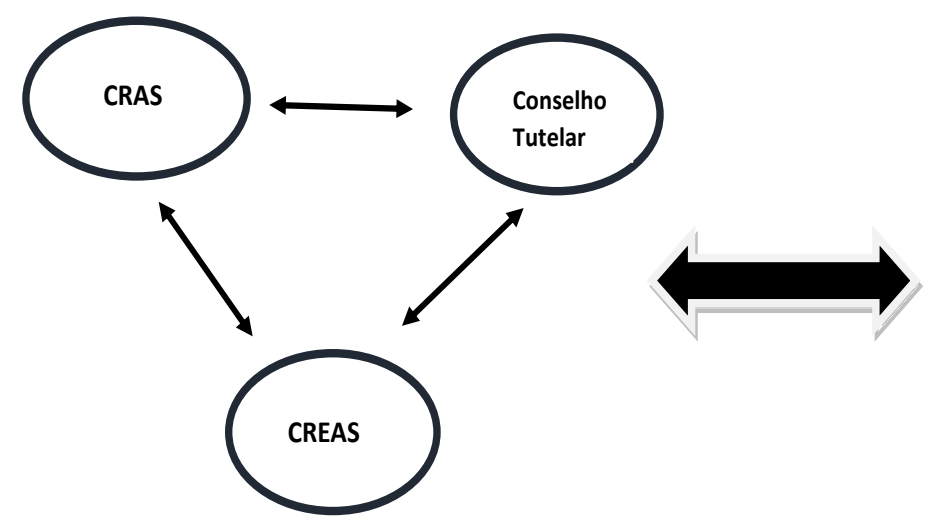

Fonte: Dados da pesquisa, 2018

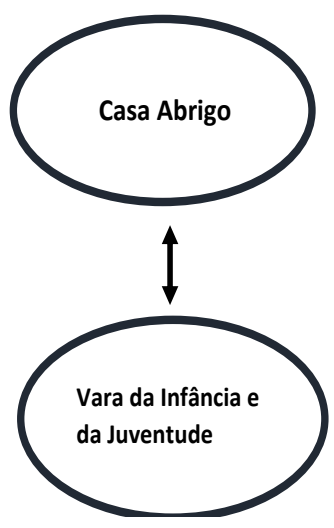

Figura 2 - Rede de Proteção Social Integral da Criança e do Adolescente de União da Vitória-PR e na adoção tardia 
A Rede de Proteção está articulada no município, mas ocorrem dificuldades no trabalho multiprofissional $^{2}$ e interinstitucional ${ }^{3}$. Cada profissional-na sua formação e atribuição-é importante para desenvolver intervenções. Cada um complementa os serviços, mas existem profissionais com certa restrição analítica da realidade realizando seus serviços de forma tecnicista, voltando seu olhar somente para uma determinada questão, desconsiderando as outras, ou seja, desprovido de olhar crítico e criterioso em relação às múltiplas variáveis implicadas no serviço prestado. Dessa forma, a Rede está em crise, os profissionais burocratizam o processo, tornando a Rede um círculo vicioso de atendimento. O tempo se torna outro aspecto complexo, pois o processo em suas múltiplas etapas é demorado e os profissionais, muitas vezes, não agilizam situações que poderiam assumir maior celeridade para a execução.

Diante dessa questão, observa-se que o ECA aborda em seus artigos a questão de atendimento. $\mathrm{O}$ artigo 86 do Estatuto da Criança e do Adolescente dispõe sobre a política de atendimento, a qual deve ser realizada por meio de um conjunto articulado de ações governamentais e não governamentais da União, dos Estados, do Distrito Federal e também dos municípios. $O$ artigo 90 do mesmo Estatuto dispõe sobre as entidades de atendimento, sendo elas responsáveis pela manutenção das próprias unidades, como também pelo planejamento e execução de programas de proteção e serviços socioeducativos destinados à criança e ao adolescente. $\mathrm{O}$ artigo 98 , do ECA define as medidas de proteção à criança e ao adolescente, as quais devem ser aplicadas sempre que os direitos reconhecidos nesta lei forem ameaçados ou violados.

Sobre a questão dos serviços profissionais que devem ser executados, as autoras Freire, Marques e Silva (2013) dizem que o assistente social no Poder Judiciário deve prestar assessoria e consultoria aos órgãos públicos judiciais, deve prestar assistência jurídica aos demais profissionais em questões que são específicas da profissão. Além disso, devem efetivar a realização de perícias e estudos sociais, informações e pareceres da área de sua competência.

Nos demais serviços da Rede o profissional deve orientar as famílias, atuar diretamente com a criança e o adolescente, visando sempre seu atendimento, mediando a garantia de seus direitos. Nessa direção, o profissional da área de psicologia deve desenvolver suas atribuições, auxiliando nas intervenções das equipes. Um depoimento de participante da pesquisa, (Vara da Infância e Juventude) argumentou que "[...] o contato com os outros profissionais é frequente e busca contribuir para a troca de saberes".

Complementam essa posição os depoimentos dos profissionais que atuam na Rede (Assistente Social do Serviço de Acolhimento, Assistente Social do CRAS, Psicóloga da Vara da Infância e Juventude, Psicóloga Serviço de Acolhimento, Conselheira Tutelar de União da Vitória$P R$ ), os quais assumiram que a instituição desenvolve atuações para a operacionalidade de Rede de Proteção Social da Criança e do Adolescente.

\footnotetext{
${ }^{2} \mathrm{~A}$ equipe multiprofissional que atua no âmbito das instituições e entidades envolvidas com o abrigamento, acompanhamento familiar e das crianças e adolescentes institucionalizadas, que integra a rede de adoção, contempla profissionais com formação em nível superior em: Psicologia, Serviço Social, Pedagogia, Direito, entre os principais envolvidos.

${ }^{3} \mathrm{~A}$ operacionalização da proteção social integral destinada às crianças e adolescentes envolve necessariamente a intersetorialidade entre políticas públicas que compõem o Sistema de Garantia de Direitos da Criança e do Adolescente. Portanto, essa articulação entre os entes do sistema compõe uma interinstitucionalidade (geralmente estão envolvidos no processo de adoção a justiça, ministério público, segurança pública, conselho tutelar, secretarias municipais de saúde, educação, assistência social e organizações da sociedade civil).
} 
Uma das questões (questão fechada: alternativas Sim ou Não) que abordou a organização e atuação da rede de proteção social integral da criança e do adolescente na adoção tardia, obteve os seguintes resultados: dos seis participantes da pesquisa dois assinalaram a resposta SIM, três assinalaram a resposta NÃO e um participante da pesquisa abriu um parêntese colocando como resposta "Não sei" (Sic. entrevistado P.S.A). Isto posto mostrou que há profissional que articula seu trabalho somente nas suas ações, desconsiderando os demais serviços ofertados pela instituição, seja de sua área ou não. Quando se faz parte de uma instituição é necessário conhecêla como um todo.

Entre as restrições que levam às dificuldades das intervenções em rede, podem ser mencionadas as resistências e/ou limitações de profissionais que não compreendem suficientemente o que a instituição oferece pelos seus serviços.

Portanto, um sistema de garantia de direitos para a criança e o adolescente significa um corpo social articulado e integrado entre Estado, famílias e sociedade civil. A garantia de direitos pauta-se em defesa, controle e promoção dos serviços prestados pelas instituições e entidades, cada uma complementa a outra, constituindo o sistema em sua totalidade.

Em um primeiro ato, os serviços e intervenções ofertados devem enfocar o restabelecimento dos vínculos da família com a criança ou adolescente. Ao se conseguir esse restabelecimento, a criança ou o adolescente podem ser desinstitucionalizados, mas o que não pode parar é o acompanhamento da equipe encarregada para consolidar as superações e evitar que a violação dos direitos não volte a ocorrer. Caso se constate reincidência, a criança e o adolescente podem voltar a ser institucionalizados e em certos casos pode ocorrer a prescrição de encaminhamento para a adoção; cada caso se torna um caso. Por isso, deve ser desenvolvido um plano de ação que assegure a articulação da atuação conjunta entre CRAS e CREAS, serviços ofertados pela saúde pública, como o Centro de Atenção Psicossocial (CAPS) nas situações de alcoolismo, na educação para regularização dos estudos, quanto à habitação, alimentação, mobilidade, trabalho e renda, ou seja, que os entes familiares sejam contemplados pelos direitos constitucionais, conforme o artigo 6 ㅇ.

\subsection{Quanto á Adoção Tardia em União Da Vitória-PR}

O processo de adoção é complexo, mas quando se trata da adoção tardia as questões se ampliam, tornando esse processo por vezes conflituoso, dado ao que foi exposto no texto acima.

Com relação às intervenções dos profissionais que respondem pelas entidades e instituições com aqueles que aguardam a adoção, segue um roteiro, conforme o relato de dois participantes da pesquisa:

\footnotetext{
Após o pedido de cadastro junto a V.IJ, o (os) pretendentes passam por avaliação psicossocial e preparo (curso), ambas etapas previstas no ECA, e obrigatórias. Após a sentença são inseridos em cadastro local e nacional, até seus dados coincidirem com uma criança apta para adoção. (Sic. Entrevistado P.V.I.J).

O município dispõe de grupo de adoção e preparo psicológico para adoção, ofertado por ONG e Poder Judiciário, que atua nesta frente (Sic. Entrevistado P.S.A).
}

Pelo exposto, o cuidado e a proteção destinados às crianças e/ou adolescentes institucionalizadas, são oportunizadas também aos que se encontram para adoção, pelos serviços de saúde, educação, assistência social, lazer, bem como as oficinas. Porém, para as crianças e adolescentes, a espera de adoção há um diferencial das intervenções que os prepara para a inserção e convivência com outra família, a da adoção. Essa preparação para a reinserção familiar deve considerar o fato de a criança e o adolescente institucionalizados se encontrarem nessa 
situação por algum dos fatores que os colocaram em situação de vulnerabilidade e risco. Portanto, o fortalecimento emocional e social deve prepará-los para uma nova experiência, na qual se espera uma convivência sem violências, sem conflitos e que as dificuldades do passado possam ter sido superadas ou em vias de superação.

As intervenções com a família que aguarda adoção, além do processo burocrático (cadastramento, frequência a curso), são monitoradas por profissionais para que ocorra coincidência entre as características das crianças e/ou adolescentes na fila da adoção, com as características desejadas pelas famílias à espera da adoção. $O$ trabalho com os possíveis adotantes no município de União da Vitória-PR ocorre no Serviço Auxiliar da Infância e da Juventude (SAIJ), que desenvolve suas ações na Vara da Infância e Juventude. O SAlJ é composto por uma equipe de duas psicólogas, uma pedagoga e um comissário da infância e juventude. As intervenções com as crianças e adolescentes que aguardam a adoção são desenvolvidas na Casa Abrigo, denominação da instituição de acolhimento do município.

Os representantes das instituições e entidades da rede socioassistencial envolvida com o processo de adoção afirmaram que este ocorre em etapas. Nesta direção, seguem abaixo três depoimentos:

Primeiramente, ocorre o processo de destituição da criança ou adolescente e os quais são incluídos no CNA (Cadastro Nacional de Adoção), e permanecem no aguardo de pretendentes habilitados e também inscritos no CNA. (Sic. A.S.S.A).

Segue as mesmas normas legais estabelecidas no ECA para todo o país. A partir da sentença que destituiu os pais, existe a necessidade de cruzar os dados dos adotantes e adotados, sendo decidido a aproximação pelo juiz. É seguido de um período de aproximação, que varia conforme a idade das crianças. Sendo identificado o vínculo, passa-se ao período de convivência, acompanhado até que se concretize a adoção (Sic. P.V.I.J).

SAIJ que desenvolve? famílias se cadastram no CNA, passam por avaliação e preparo (o qual o Acolhimento participa, pois conhece a realidade das crianças acolhidas; após os tramites legais, ficam habilitados e são inseridos no CNA. As crianças, após esgotadas as possibilidades de reinserção familiar, passam por processo de destituição do poder familiar e após trânsito julgado é inserido no CNA e aguardam pretendentes. Quem faz o link entre criança e adolescente é o SAIJ (Sic. P.S.A).

A adoção, independente se tardia ou não, deve seguir os trâmites orientados pelas legislações, em especial o contido no ECA e no Cadastro Nacional de Adoção (CNA). Este cadastro é o que dá aporte aos juízes da Vara da Infância e Juventude na condução de procedimentos e processo de adoção em todo o país, colocando a criança e o adolescente como sujeitos principais do processo, na busca de uma família que os acolham.

Diante da existência de processos de adoção tardia no município de União da Vitória-PR, se investigou acerca dos mitos e preconceitos que interferem no procedimento legal da adoção. Camargo (2006) aponta que os mitos que existem na atual cultura da adoção no Brasil se colocam como obstáculos à realização de adoções de crianças chamadas pelo autor de idosas, pois aumentam as crenças e expectativas negativas ligadas à adoção tardia.

A questão dos mitos e preconceitos sobre a adoção perpassa por todas as famílias que pretendem adotar, gera-se certa fantasia de situações que não são realidade, mas o medo do desconhecido acarreta dificuldades no entendimento sobre a adoção tardia que faz com que 
empecilhos aconteçam no meio do processo, conforme argumenta um participante da pesquisa que atua na rede socioassistencial.

A dificuldade de encontrar pretendentes para a adoção quanto mais avançada a idade do adotando. A dificuldade de adaptação - quando ocorre a adoção - muitas vezes resulta no insucesso da adoção (Sic. A.S.S.A).

A adoção tardia é perpassada pelas opções dos pretendentes que preferem adotar crianças com idades inferiores a dois anos. O medo e a insegurança engessam tais pretendentes de vislumbrarem novos desafios. Adotar não é só criar e educar, mas sim é um processo de amor e dedicação contínua. Em especial, com a realização dos testes de convivência, a fim de se mostrar que a relação de afeto vai acontecendo até as pessoas se sentirem seguras e protegidas na nova família. Essa construção oportuniza aos pretendentes menos preparados adaptarem-se com as diversas situações que se farão presentes no cotidiano dessa família, com o intuito de evitar uma possível devolução.

Mas, aqueles que estão bem preparados, informados, conseguem lidar melhor com essa questão, e gradativamente fortalecem os vínculos entre os adotantes e adotados.

Diante dessa questão, nota-se a importância das intervenções em rede e das equipes técnicas para preparar os possíveis adotantes para todos os desafios colocados na busca da concretização da adoção, que envolve todos os setores, em especial e mais enfaticamente com aquelas crianças e adolescentes institucionalizados que aguardam a adoção, para apoiar nas questões psicológicas, emocionais, sociais, familiares, na busca da garantia de direitos, para esses que já tiveram seus direitos violados.

Freire, Marques e Silva (2013) argumentam que na adoção tardia, por mais que os adotantes sejam preparados, sempre será uma situação de risco que requer cuidados especiais no período crítico de adaptação.

A adoção tardia, em suma, deveria ser prevenida por uma conscientização por parte dos pretendentes e de toda a sociedade brasileira. A adoção em qualquer tempo é a realização de desejos pessoais, familiares e sociais. É um processo de acolhimento, e a adoção tardia, além de envolver amor, requer, também, conscientização. Por isso, é importante promover o debate sobre o tema, para que as adoções possam ser realizadas da melhor forma possível, ou seja, com seriedade, segurança, tranquilidade e com a melhor harmonia possível entre adotante e adotado.

\section{CONSIDERAÇÕES FINAIS}

A adoção tardia de crianças e adolescentes institucionalizados no Brasil, após o ECA vem sendo conduzida sob criterioso processo, em vista das particularidades que cercam a situação de cada um dos entes envolvidos. A pesquisa mostrou que, em União da Vitória-PR, a adoção e a adoção tardia são orientadas pela mesma legislação e que há composição de uma rede envolvida conduzindo o processo.

De um lado, cada vez mais a preocupação com a proteção social integral ao ser em desenvolvimento. As condições às quais estavam expostas foram determinantes para sua institucionalização. Violências sofridas (sexual, negligências, física, psicológica) são recorrentes nos casos de crianças e adolescentes que se tornaram responsabilidade do Estado.

Por outro lado, e paradoxalmente, à guisa dos arranjos familiares, o sentido de convivência com a concepção filho, realizando desejos íntimos de maternidade e/ou paternidade, estimulam pessoas a recorrerem à adoção de crianças ou adolescentes que se encontram institucionalizadas. 
Nesse contexto, é necessário apontar que ocorreram transformações sobre o modo clássico da disponibilização e busca por um filho adotivo dos acordos informais. A rigidez da legislação foi necessária visando conduzir um processo ético e que possa assegurar à criança e/ou adolescente uma condição de segurança e proteção.

Concepções de dignidade da pessoa humana, sujeito de direitos, seres em desenvolvimento foram priorizados em detrimento de sua situação temporal de institucionalização. Ainda que a preservação da integridade física, moral, emocional, intelectual e social são atribuições constitucionalmente assumidas pelo Estado. Para construir cenários que revertessem os casos dos riscos sociais, ocorreu também uma transformação no âmbito da institucionalidade. Uniram-se justiça, segurança pública, sociedade civil organizada, setores da esfera governamental na aceleração da atualização da legislação, na composição de estruturas físicas e legais para preservar as condições de desenvolvimento da criança e do adolescente, como a pesquisa mostrou ocorrer em União da Vitória-PR.

Diante de tais perspectivas, se ressaltam as responsabilidades dos profissionais da área que operacionalizam os serviços de acolhimento, institucionalização e envolvidos com a adoção tardia. Afinal, é por meio destes profissionais que os serviços são ofertados e a adoção é concretizada com a determinação final do juiz da Vara da Infância e Juventude.

Os aportes teóricos, legais e jurídicos sobre a adoção tardia, nos fazem conhecer que há entraves nesse processo ainda, no que tange aos argumentos que dificultam os encaminhamentos, bem como, os medos, inseguranças e os mitos encontrados. A cultura preserva valores do bom, belo, da perfeição, que geram estigmas sobre crianças e adolescentes cujas famílias biológicas não tiveram condições de continuar com sua responsabilidade de cuidado e de convivência.

A adoção tardia revela contradições no modo de pensar e de agir perante a vida. De um lado há o quem tenha sido exposto às vulnerabilidades, do outro, um ser humano que nutre a concepção e o sentimento de ser o aporte do bem-estar, da preservação da integridade e do respeito à dignidade do ser humano, como compromisso que transcende a mera condição biológica e alcança uma postura ética e estética diante da vida, sobretudo do mundo da vida.

\section{REFERÊNCIAS}

ANDREI, Elena. Adoção: mitos e preconceitos. In: FREIRE, Fernando (Org). Abandono e Adoção: contribuições para uma cultura da adoção. Curitiba: Terra dos Homens, 2001. p. 41-50.

AVANSINI, Carolina. Morosidade reduz chances de adoção. Folha de Londrina. Londrina, mar. 2017. Disponível em: <https://www.folhadelondrina.com.br/geral/morosidade-reduz-chances-deadocao-973377.html>. Acesso em: 07 de maio de 2018.

BIROLI, Flávia. Família: Novos Conceitos. São Paulo: Editora Fundação Perseu Abramo, 2014. Disponível em: <http://redept.org/uploads/biblioteca/colecaooquesaber-05-com-capa.pdf>. Acesso em: 09 de março de 2018.

BRASIL, Constituição (1998). Constituição da República Federativa do Brasil. Brasília: Senado Federal, 1988. 
BRASIL. Estatuto da Criança e do Adolescente. Lei 8.069/90, de 13 de julho de 1990. Brasília: Senado Federal, 1990.

BRASIL. Orientações Técnicas: serviços de acolhimento para crianças e adolescentes. Brasília, Ministério do Desenvolvimento social, 2009. Disponível em:

$<$ http://www.mds.gov.br/cnas/noticias/orientacoes tecnicas final.pdf $>$. Acesso em: 25 de abril de 2018.

BRASIL. Tipificação Nacional de Serviços Socioassistenciais: texto da Resolução 109 de 11 de novembro de 2009. Brasília- DF: Impressão Nacional, 2009.

CAMARGO, Mário Lázaro. Adoção tardia: Mitos, medos e expectativas. São Paulo: Edusc, 2006.

CONSELHO NACIONAL DE JUSTIÇA (CNJ). Passo a Passo da Adoção. Disponível em: $<$ http://www.cnj.jus.br/programas-e-acoes/cadastro-nacional-de-adocao-cna/passo-a-passo-daadocao >. Acesso em: 19 de março de 2018.

DIAS, Maria Berenice. Manual de direito das famílias. 10 ed. São Paulo: Revista dos Tribunais, 2015.

EISENSTEIN, Evelyn. Adolescência: definições, conceitos e critérios. Rev. Adolescência e Saúde. Rio de Janeiro, v. 2, n. 2, 2005. Disponível em:

<http://www.adolescenciaesaude.com/detalhe artigo.asp?id=167>. Acesso em: 19 de março de 2018.

FREIRE, Débora Rodriguez; MARQUES, Valquiria; SILVA, Yuri Emmanuelle. Adoção Tardia e o Trabalho do Assistente Social. III Simpósio Mineiro de Assistentes Sociais. Belo Horizonte, 07-09 jun. 2013. Disponível em: <http://www.cress-

mg.org.br/arquivos/simposio/ADO\%C3\%87\%C3\%830\%20TARDIA\%20E\%200\%20TRABALHO\%20D O\%20ASSISTENTE\%20SOCIAL.pdf>. Acesso em: 03 de abril de 2018.

NOGUEIRA NETO, Wanderlino. Por um Sistema de Promoção e Proteção do Direitos Humanos de Crianças e Adolescentes. Revista Serviço Social e Sociedade. São Paulo: Cortez, v.26, n.83, p.06-25, 2005.

SILVA, Maria Liduina de Oliveira e. O Estatuto da Criança e do Adolescente e o Código de Menores: descontinuidades e continuidades. Revista Serviço Social e Sociedade. São Paulo: Cortez, v.26, n.83, p.30-48, 2005.

SIMON, Claudio Hutz. Violência e risco na infância e adolescência: Pesquisa e intervenção. São Paulo: Casa do psicólogo, 2005.

VARGAS, Marlizete Maldonado. Adoção Tardia: da família sonhada à família possível. São Paulo: Casa do Psicólogo, 1998.

VERONESE, Josiane Rose Petry; OLIVEIRA, Luciene Cássia. Adoção e Relações Familiares. Florianópolis: Katálysis, v.0, n.02, p.50-56, 1998. 
WASKIEWIC, Maikon. Mapa de localização do município de União da Vitória (PR). Canoinhas, 2020. 